\title{
The Impact and Influencing Path of the Pilot Carbon Emission Trading market--Evidence From China
}

\author{
Wangzi $X u^{*}$ \\ School of Public Health, Xiamen University, Xiamen, China
}

As the country with the largest $\mathrm{CO}_{2}$ emissions in the world, the Chinese government has put forward clear goals of hitting peak carbon emissions by 2030 and carbon neutralization by 2060. Thus, China started piloting carbon emission trading in 2013, and in July 2021 China opened national carbon trading, which is the largest carbon market in the world (China Launches World, 2021). Therefore, it is very important for China to study the role and mechanism of carbon trading at present. Based on the quasi-natural experiment of China's carbon market pilot, this paper uses panel data of 30 provinces in mainland China from 2008 to 2019 to conduct an empirical study on carbon emission reduction and the

OPEN ACCESS

Edited by:

Zhen Wang,

Huazhong Agricultural University,

China

Reviewed by: Luigi Aldieri,

University of Salerno, Italy

Santosh Kumar Karn,

Sardar Bhagwan Singh University,

India

*Correspondence:

Wangzi $X u$

xuwangzi1016@163.com

Specialty section:

This article was submitted to

Environmental Economics and

Management,

a section of the journal

Frontiers in Environmental Science

Received: 01 October 2021

Accepted: 27 October 2021

Published: 01 December 2021

Citation:

Xu W (2021) The Impact and Influencing Path of the Pilot Carbon Emission Trading market-- Evidence

From China.

Front. Environ. Sci. 9:787655 doi: 10.3389/fenvs.2021.787655 economic effects in China's pilot provinces through a Time-varying Differences-inDifferences method model. The results show that the implementation of a carbon trading policy can significantly inhibit carbon emissions and promote economic growth. At the same time, this paper further analyzes the emission reduction mechanism of the carbon emissions trading policy through the intermediary effect test and finds that the policy mainly realizes carbon emission reduction by changing the energy consumption structure, promoting low-carbon innovation, and upgrading the industrial structure. In addition, innovative research has found the impact of a carbon price signal and marketization on the emission reduction effect of the carbon market. Finally, targeted suggestions are put forward.

Keywords: differences-in-differences, China's ETS, carbon price signal, intermediary effect, marketization

\section{INTRODUCTION}

As Chinese President Xi Jinping committed in his speech at the seventy-fifth UN General Assembly, China will strive to hit peak carbon dioxide emissions by 2030 and become carbon neutral by 2060 (Zhong et al., 2021). This pledge Expressed China's determination to contribute to protecting the world's ecological environment, promoting the green comprehensive transformation of economic and social development. However, China continues to be the country with the largest carbon emissions in the world (Wu et al., 2021a). According to BP (2021) in 2019, total global carbon emissions are 34,169 MT, and China's carbon emission was 9,825.8 MT, accounting for $28.8 \%$ of the world total. In contrast, the EU and the United States account for 10.9 and $14.5 \%$ of the world's carbon emissions, respectively, while the total carbon emissions of the Asia Pacific region other than China account for only $21.7 \%$ of the world's total carbon emissions. It can be seen from these data that China still has a long way to go in carbon emission reduction. The carbon market is a financial market in the background of a low-carbon economy; dealers trade $\mathrm{CO}_{2}$ emission rights in the permitted market through mandatory rules or spontaneous behavior. The cost of carbon emissions is 
transformed into the production cost of enterprises by the pricing of emission rights (Hua and Dong, 2019), thus, as a major institutional innovation to promote green and low-carbon development, carbon emission trading has become an important policy tool for China to reduce greenhouse gas emissions economically and efficiently by using flexible market economic means (Wu et al., 2021b). After an 8-year pilot period starting in 2013, China's carbon emission trading market was officially launched on July 16, 2021. Therefore, studying the impact of the carbon market policy on the carbon dioxide emissions and economy of pilot provinces and clarifying the mechanism of carbon emission reduction effect of the carbon trading market is of great significance to China, which now has the largest carbon market covering carbon emissions in the world (Chinese government, 2021).

So far, a large number of studies have confirmed the effectiveness of carbon market policy which is considered as a tool to reduce emissions at a lower cost (Lo, 2012), for example, Tang et al. Constructed a computable general equilibrium model to simulate the emission reduction effect and economic impact of the national carbon market policy (Tang, 2020), Chen Wei dong et al. used panel quantile regression to investigate the economic effects of carbon emissions in 30 provinces in China from 2000 to 2012, and found that medium-level carbon emissions have a significant role in promoting the economy (Chen and Jin, 2016). Meanwhile, many studies on the pilot policies of China's carbon market have emerged recently, for example (Gao et al., 2020), use DID and DDD and the provincial panel data from 2005 to 2015 to evaluate the carbon reduction effect of China's ETS; Dong Xuan et al. (2020) examine the impact and impact channel of China's pilot carbon market using DID model (Xuan et al., 2020); Haijun Zhang et al. also affirmed the carbon emission mitigation effect of China's ETS using China's provincial panel data (Zhang et al., 2019). However, these studies often ignore the time difference between the implementation of policies in each pilot province and exclude Sichuan, and Fujian which implemented the policy relatively late. Besides, the existing literature focuses on the environmental and economic impact of carbon market policy, while discussion on the direct and indirect impact mechanism of carbon market policy is scarce. Hence, this paper is committed to verifying the effect of the carbon market on emission reduction and economic growth and studying the mechanisms thereof. In addition, this paper creatively discusses the emission reduction effect of the carbon market from the perspective of the carbon price and marketization.

\section{THEORETICAL BASIS AND HYPOTHESIS}

First of all, in the classic Coase theory, by clearly defining property rights (Coase, 1960), the carbon market can make public resources tradable like commodities so it can restrict the production and operation behavior of enterprises, balancing the contradiction between economic development and carbon emission reduction with the help of market mechanisms (Fernández-Amador et al., 2017), and urge enterprises to strive for carbon emission reduction while chasing economic profits as the cost of environmental pollution caused by their production behavior may be unacceptable. In order to avoid the additional cost of increasing excessive emissions, enterprises will effectively utilize the given carbon emission quotas, and due to the existence of the carbon market, enterprises may choose to buy or sell quotas according to their own conditions and profit from emission reduction through market transactions. That is, when the carbon price in the trading market is higher than the marginal emission reduction cost, enterprises can choose to obtain the remaining emission quota by increasing the emission reduction intensity, and make profits by selling the excess quota in the trading market; Enterprises can also choose to keep carbon emissions within the allowable quota to avoid additional costs. Moreover, the carbon trading market can allow enterprises to choose low carbon emission technologies, so as to reduce the overall cost of emission reduction (Anger, 2008). Based on the above analysis, the first research hypothesis of this paper is proposed:

Hypothesis 1: A carbon emission trading policy can reduce the carbon dioxide emissions of pilot provinces.

In terms of economic effect, carbon emission trading can affect economic development by affecting enterprise production decisions and business activities. At the initial stage of implementing the carbon trading policy, the economic profits of enterprises may be adversely affected by the increase of costs, but environmental regulation will promote enterprises to carry out technological innovation or adopt emerging technologies to improve their production efficiency and productivity so as to improve their market competitiveness and profitability; the increased cost of environmental protection will be offset and eventually bring economic growth (Wu, 2018). The role of carbon emission trading on economic development has also been confirmed by existing research (Roman and Welsch, 2008). We can then draw the second hypothesis:

Hypothesis 2: A carbon emission trading policy can promote the economic growth of the pilot areas.

Besides, as the marginal cost of energy input is increased, under the effect of cost pressure and market incentives, and emission controls are brought by carbon market policy, enterprises will tend to apply clean energy and other new technologies to improve efficiency and reduce emissions by optimizing their energy structure (Huang et al., 2018). Moreover, carbon emission trading can significantly promote the green technology innovation of enterprises (Lili and Ren, 2021), as innovation helps the reduction of carbon emission and there are extra economic benefits that can be obtained by selling redundant carbon emission quotas. Additionally, the carbon trading market can realize carbon emission reduction by adjusting the industrial structure. The carbon emission trading market mainly covers key emission industries such as the petrochemical, chemical, and steel sectors. By strengthening the constraints on these highcarbon industries, enterprises are stimulated to adjust their business direction and turn from industries with high energy consumption and high emission in industries with low energy 
consumption and less pollution, forced industrial transformation, adjustment, and upgrading of enterprises. On account of the theories above, we can propose the following assumption for the mechanism of carbon reduction effect of the carbon market:

Hypothesis 3: The carbon trading market policy can achieve carbon emission reduction by optimizing the energy consumption structure, promoting green technology innovation, and stimulating industrial structure adjustment.

The carbon price signal is the core function of the carbon market (Lili and Ren, 2021), and can play a cost constraint role under the carbon market mechanism. Under the premise of cost constraint, the carbon price signal will lead to a decline of the product competitiveness of carbon emission-intensive industries, and part of its market share will be gradually replaced by lowcarbon products. Therefore, in the long run, the carbon price signal will provide a new driving force for the transformation of industrial structure to green and low-carbon, so as to help carbon emission reduction. The stable and effective carbon price signal helps to force industrial transformation and upgrading, eliminate backward production capacity, and implement supply-side structural reform by using environmental policies (Fu and Zou, 2017). In addition, the change of carbon price has an incentive effect on enterprise green technology innovation. When the carbon price is high enough, the high fossil energy consumption industry will face rising production costs and shrinking demand at the same time, and the expected profit will be reduced. Relatively, the expected profit of the low fossil energy consumption industry will rise, so that enterprises will invest capital and human resources in lowcarbon technology research activities, forcing enterprises to carry out the transformation and upgrading and green technology innovation. Therefore, the rise of low-carbon technology innovation level under the role of carbon price policy further promotes the output growth of low-carbon industry through economic production function and promotes the effect of carbon emission reduction at the technical level.

Carbon market policy can achieve emission reduction through the market mechanism with carbon trading as the core, which means the market mechanism is an important part of the carbon market to achieve emission reduction. The degree of marketization represents whether the market mechanism is perfect. Therefore, the degree of marketization should have a great impact on the emission reduction effect of the carbon market (Yin-yin et al., 2021). When the carbon transaction cost is positive, defining the subject ownership of different carbon quotas will bring different efficient resource allocations. In the carbon market, the price determines the scale of emission reduction ( $\mathrm{Hu}$ and Ding, 2020). If the carbon emission right is sufficient, even changing the carbon quota or distribution method will not improve the carbon emission level, only when the carbon trading price rises will enterprises increase carbon emission reduction investment in order to obtain emission reduction benefits (Huang et al., 2016). As we discussed above, in Coase theory, the carbon can restrict the production and operation behavior of enterprises with the help of market mechanism, thus, the degree of marketization will help the carbon market to give full play to the role of market mechanism to effectively realize carbon emission reduction in a cost-effective way (Kou, 2021). Besides, the degree of marketization is related to market transparency. The higher the degree of marketization, the better the information disclosure of the carbon market ( $\mathrm{Li}$ et al., 2019) and the lower the transaction cost of the carbon market, so as to make the carbon market operate better and play a better role in emission reduction. On the basis of the theories above, this paper conducts further research:

Hypothesis 4: Marketization and carbon price signal can affect the carbon reduction effect of carbon market policy.

\section{EMPIRICAL DESIGN}

\section{Research Method}

This paper uses the Time-varying DID to evaluate the impact of carbon emission trading policy on carbon emission reduction and economic growth. The DID model divides the variables in the natural experiment into the treatment group and the control group to evaluate the effect of a policy. By controlling the systematic differences between the two groups, it obtains the net effect of the policy (Imbens and Wooldridge, 2009).

The basic idea of this paper is to regard the pilot provinces of carbon emission trading as the experimental group and treat the provinces which have not implemented the policy as the control group. The net effect of this policy can be judged by comparing the impact of carbon emission trading on the experimental group and the control group. In this paper, the experimental group includes eight carbon emission trade pilot provinces: Beijing, Guangdong, Tianjin, Shanghai, Hubei, and Chongqing, which begin to implement the policy in 2013 and 2014; and Fujian and Sichuan which started from 2016 to 2017 . Tibet is exempt from this research due to missing data, so the control group includes the other 22 provinces of mainland China except for the experimental group and Tibet. After dividing the experimental and control group, this paper constructs the regional dummy variable Treatment and time dummy variable Time, Treatment $=1$ corresponds to the experimental group, including Beijing, Shanghai, Tianjin, Guangdong, Hubei, Chongqing, Sichuan, and Fujian; Treatment $=0$ represents the 22 provinces which belong to control group; Time $=1$ only in the years when the pilot areas implement the carbon market policy, for non-pilot areas and the year when pilot areas do not open carbon market, Time $=0$. Then, the interaction term Trial is obtained by Treatment ${ }^{\star}$ Time, which indicates that Trial $=1$ when the carbon market policy is implemented in the pilot area. Finally, a two-way fixed effect model is used to estimate the models constructed which adopt Trial as the explanatory variable to get the time-varying DID regression results.

\section{Variables and Data Variable Meanings}

The specific meanings of explained variables, explanatory variables and control variables in this paper are shown in Table 1.

We believe that the provincial per capita primary energy production divided by the national per-capita primary energy 
TABLE 1 | Variables.

\begin{tabular}{|c|c|c|c|}
\hline Classification & $\begin{array}{l}\text { Variable } \\
\text { name }\end{array}$ & Variable meaning & Computing method \\
\hline & $\operatorname{lnCO} 2$ & Carbon dioxide emissions & $\begin{array}{l}\text { Calculate the carbon dioxide emission of each region according to IPCC6006 method, and take } \\
\text { the logarithm }\end{array}$ \\
\hline \multirow[t]{3}{*}{ Explained variable } & CO2int & Carbon intensity & CO2 emissions/nominal GDP \\
\hline & LnGDPave & Rea GDP per capita & The logarithm of nominal per capita GDP multiplied by GDP index divided by 100 \\
\hline & Treatment & $\begin{array}{l}\text { Regional policy dummy } \\
\text { variable }\end{array}$ & Non pilot area: Treatment $=0$, Pilot area: Treatment $=1$ \\
\hline \multirow[t]{4}{*}{ Explanatory variable } & Time & Time dummy variable & Time $=0$ before policy implementation and Time $=1$ after policy implementation in the pilot area \\
\hline & Trial & Interaction term & Treatment ${ }^{\star}$ Time \\
\hline & Structure & Energy structure & 1-(Regional coal consumption/total energy consumption) \\
\hline & GDP & Economic scale & Real GDP takes logarithm \\
\hline \multirow{5}{*}{$\begin{array}{l}\text { Control variables } \\
\mathrm{X}_{1 \text { it }}\end{array}$} & Pop & Resident population & The number of permanent residents in each region take logarithm \\
\hline & Industry & industrial structure & Added value of secondary industry/added value of tertiary industry \\
\hline & Endowment & Energy endowment & Per capita regional primary energy production/national per capita primary energy production \\
\hline & Patent & $\begin{array}{l}\text { Scientific and technological } \\
\text { level }\end{array}$ & Regional authorized patents \\
\hline & Market & Marketization index & 2008-2016 from the report, 2017-2019 from trend forecast \\
\hline \multirow{3}{*}{$\begin{array}{l}\text { Control variables } \\
\mathrm{X}_{2 \text { it }}\end{array}$} & Trade & Import and export trade & Total imports and exports/nominal GDP \\
\hline & Pop & Resident population & The number of permanent residents in each region take logarithm \\
\hline & Urban & Urbanization rate & Urban population/resident population \\
\hline
\end{tabular}

TABLE 2 | Summary statistics.

\begin{tabular}{lccccc}
\hline Variable & Obs & Mean & Std. Dev & Min & Max \\
\hline Treatment & 360 & 0.2666667 & 0.4428321 & 0 & 1 \\
Time & 360 & 0.122 & 0.328 & 0 & 1 \\
Trial & 360 & 0.122 & 0.328 & 0 & 1 \\
$\mathrm{CO}_{2}$ int & 360 & 2.06 & 1.58 & 0.273 & 7.63 \\
InCO $_{2}$ & 360 & 10.124 & 0.76 & 7.692 & 11.52 \\
InGDPave & 360 & 10.567 & 0.512 & 9.196 & 11.774 \\
GDP & 360 & $19,775.33$ & $16,440.99$ & $1,018.62$ & $89,410.15$ \\
Market & 360 & 6.44 & 1.948 & 2.33 & 11.518 \\
Industry & 360 & 0.956 & 0.309 & 0.191 & 1.897 \\
Pop & 360 & $4,521.672$ & $2,711.412$ & 554 & 11,521 \\
Paptent & 360 & $43,371.06$ & $68,928.77$ & 228 & 527,390 \\
Urban & 360 & 55.801 & 13.044 & 29.11 & 89.6 \\
Trade & 360 & 0.282 & 0.329 & 0.0127 & 1.698 \\
Endowment & 360 & 1.376 & 2.068 & 0.009 & 9.894 \\
Structure & 360 & 0.324 & 0.305 & -0.758 & 0.982 \\
& & & & &
\end{tabular}

production is a reasonable alternative index of energy endowment as it not only takes into account the actual energy production capacity but also eliminates the impact of population size (Zhao et al., 2013). Besides, as the main source of carbon emission in China is coal consumption, the proportion of coal consumption in the total energy consumption represents the energy consumption structure well.

\section{Data Sources and Processing}

All the raw data come from the yearbook of China and the yearbook of each province, as well as the China energy statistical yearbook from 2009 to 2020. Additionally, some of the data is from the National Bureau of Statistics (National data, China National Bureau of Statistics, 2021).

The data of the variable "Market" come from a research report (Marketization Index of China's Provinces, 2018), but it only

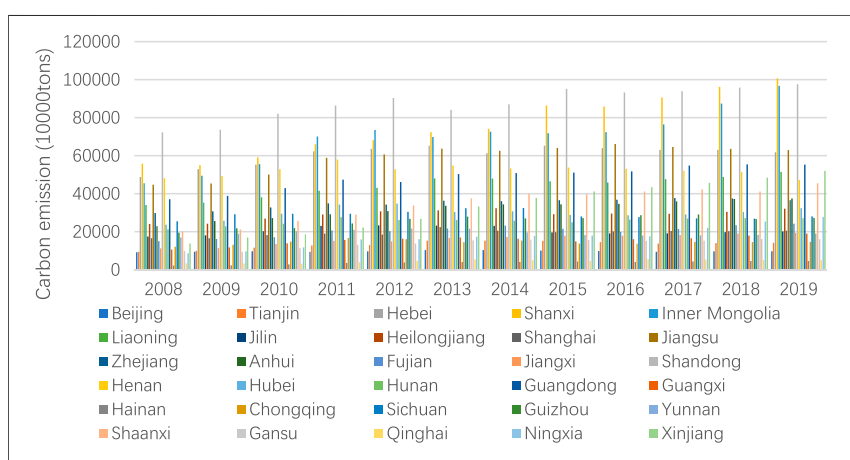

FIGURE 1 | Carbon emission of 30 provinces in China,2008-2019.

reports the indexes from 2008 to 2016, so the indexes from 2017 to 2019 are forecasted based on trends. Also, some of the data of provincial per capita primary energy production is missing, they are obtained by converting the output of raw coal, crude oil, and natural gas from China's energy statistical yearbook into standard coal and summing them up.

The summary of statistics is illustrated in Table 2 .

The method of measuring $\mathrm{CO}_{2}$ emissions and carbon intensity in this paper is to calculate energy-related $\mathrm{CO}_{2}$ emissions (CE) of each region through energy consumption, average calorific value, and carbon emission coefficient according to the method given by the Intergovernmental Panel on climate change (IPCC 2006). In this paper, we use three primary energy consumption sources to calculate $\mathrm{CO}_{2}$ emission.

$$
\mathrm{CO}_{2}=\sum_{\boldsymbol{i}=1}^{3} E \boldsymbol{C}_{\boldsymbol{i}} \times \boldsymbol{\delta}_{\boldsymbol{i}} \times \mathrm{EF}_{\boldsymbol{i}}
$$




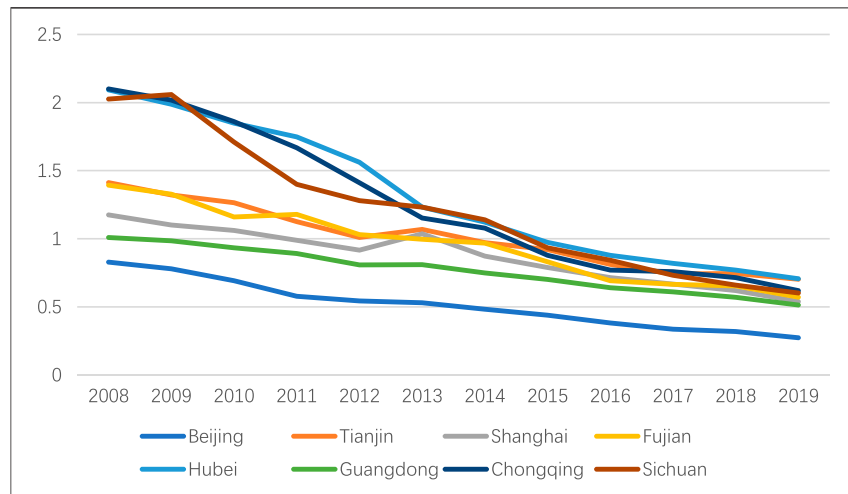

FIGURE 2 | Carbon intensity change of pilot areas.

Where $\mathrm{CO}_{2}$ represents the total carbon dioxide emission, $\mathrm{I}=1,2,3$ represents coal, oil, and natural gas, respectively; $\mathrm{EC}_{\mathrm{i}}$ represents the consumption of these three energy sources; $\delta_{\mathrm{i}}\left(\mathrm{kgce} / \mathrm{kg}\right.$ or $\left.\mathrm{kgce} / \mathrm{m}^{3}\right)$ is the standard coal conversion coefficient of energy, $\mathrm{EFi}$ (tCO2/tce) is the carbon dioxide emission coefficient of the $i$ th fuel (Guidelines for the preparation of provincial greenhouse gas inventories, 2014) Carbon intensity is measured by $\mathrm{CO}_{2}$ divided by nominal GDP.

Figure 1 establishes the carbon emissions of 30 provinces in China from 2008 to 2019.

As can be seen from Figures 1, 2, China's carbon emissions are not only large, but also increasing year by year, which means that China is under great pressure on emission reductions. Besides this, the carbon emission intensity of the eight pilot areas decreased year by year, with a decrease of more than $50 \%$, and the carbon intensity of the pilot areas continues to decline after the implementation of the carbon market policy.

\section{Model Construction}

Based on time-varying DID and the variables explained above, the model of emission reduction effect and economic effect was constructed as follows:

$$
\begin{aligned}
& \operatorname{lnCO}_{2 i t}=\alpha_{1}+\beta_{1} \text { Trial }_{1 i t}+\beta_{2} X_{1 i t}+\mu_{1 i}+\varphi_{1 t}+\varepsilon_{1 i t} \\
& \text { InGDPave }{ }_{i t}=\alpha_{2}+\beta_{3} \text { Trial }_{2 i t}+\beta_{4} X_{2 i t}+\mu_{2 i}+\varphi_{2 t}+\varepsilon_{2 i t}
\end{aligned}
$$

In the two models, $\mu_{1 i}, \mu_{2 i}$ indicates regional fixed effect, $\varphi_{1 \mathrm{t}}, \varphi_{2 \mathrm{t}}$ represents time fixed effect, $\varepsilon_{1 \mathrm{it}}, \varepsilon_{2 \mathrm{it}}$ is the random error term. Coefficient $\beta_{1}, \beta_{2}$ measure the impact of carbon emission trading policy on carbon emission reduction and economic growth, respectively. $\mathrm{i}$ and $\mathrm{t}$ represent the $i$ th province and the $t$ th year, respectively ${ }^{1}$.

\section{EMPIRICAL RESULTS AND ANALYSIS}

\section{Parallel Trend Test}

DID has an important premise assumption-a parallel trend assumption, which assumes that the changing trend of the

${ }^{1}$ Remark: the Model of lnCO2int Is the Same as Model (1), the Control Variables $\mathrm{X}^{3 i t}$ Include Patent, endowment, industry, pop, urban. treatment group and the control group before the event is the same. For the parallel trend test, the following models are constructed based on model (1), (2):

$$
Y_{i t}=\alpha+\sum_{j=-m}^{n} \beta_{j} \text { Policy }_{i, t-j}+\gamma X_{i t}+\mu_{i}+\varphi_{t}+\varepsilon_{i t}
$$

Where $\mathrm{Y}_{\text {it }}$ can be three explained variables $\ln \mathrm{CO}_{2}, \mathrm{CO}_{2}$ int, and lnGDPave; Policy $i_{i} t-j$ is a dummy variable, if Province $i$ implements carbon trading policy during the $t-j$ period, the value of this variable is 1 , otherwise it is $0(\mathrm{~m}$ and $\mathrm{n}$ represent the number of periods before and after the policy time point, respectively). Pre5, Pre4, Pre3, Pre2, Pre1, Current, and Post1 are all dummy variables, indicating the observed values in the 5, 4, 3, 2 years, and 1 year before, the current year and the next year of the implementation of the carbon emission trading policy. The remaining variables are the same as model (1) and model (2) (Wang and Yao, 2021).

It can be seen from Table 3 that the coefficients of Pre5-Pre1 in all models do not pass the significance test, demonstrating that the changing trend of carbon dioxide emissions and carbon intensity of the experimental group and the control group before the implementation of the policy is the same, and the changing trend of per capita GDP of the two groups is the same, the parallel trend assumption is passed.

\section{Benchmark Regression Results}

The regression results are presented in Table 4. Each column controls the fixed effect of province and time. Column 1) does not add control variables while column 2 ) adds control variables. The results in Table 4 depict that the coefficient of Trial in the regression of the explained variables $\operatorname{lnCO}_{2}, \mathrm{CO}_{2}$ int is significantly negative at the level of 1 and $5 \%$, respectively regardless of whether the control variable is put in or not, and the coefficient of Trial of lnGDPave is always significantly positive at the level of $1 \%$. The value of the coefficient of Trial in the model of $\mathrm{CO}_{2}$ int added the control variable reflects that this policy can reduce the carbon intensity of the pilot area by $12.77 \%$, which is significant at the level of $5 \%$. These demonstrate that the implementation of a carbon emission trading policy can significantly reduce the $\mathrm{CO}_{2}$ emission level and carbon

TABLE 3 | Parallel trend test results.

\begin{tabular}{lccc}
\hline & InCO2 & CO2int & LnGDPave \\
\hline Pre5 & -0.0052152 & 0.0719899 & -0.001561 \\
Pre4 & 0.0515375 & -0.0535332 & -0.0015882 \\
Pre3 & 0.0151672 & 0.0085686 & 0.0077435 \\
Pre2 & -0.0052839 & 0.0301947 & -0.0011926 \\
Pre1 & $-0.0259,418$ & 0.0098251 & 0.0127517 \\
Current & $-0.0342,268$ & $0.0634176^{\star}$ & $0.032229^{\star}$ \\
Post & $-0.1406753^{\star \star}$ & $0.6202212^{\star \star \star}$ & $0.0402379^{\star \star}$ \\
Constant & $9.013364^{\star \star \star}$ & 3.41314 & $6.967298^{\star \star \star}$ \\
Controls & Yes & Yes & Yes \\
Time, province fixed effects & Yes & Yes & Yes \\
Observations & 360 & 360 & 360 \\
Within-R2 & 0.3037 & 0.6281 & 0.9212 \\
\end{tabular}

${ }^{1}$ Note:t-values are in parentheses, ${ }^{* * *} \mathrm{p}<0.01,{ }^{* *} \mathrm{p}<0.05,{ }^{*} \mathrm{p}<0.1$. 
TABLE 4 | DID regression results.

\begin{tabular}{|c|c|c|c|c|c|c|c|c|}
\hline \multirow[t]{2}{*}{$\mathbf{x}$} & \multicolumn{2}{|c|}{$\mathrm{InCO}_{2}$} & \multirow[t]{2}{*}{$\mathbf{x}$} & \multicolumn{2}{|c|}{$\mathrm{CO}_{2}$ int } & \multirow[t]{2}{*}{$\mathbf{x}$} & \multicolumn{2}{|c|}{ InGDPave } \\
\hline & (1) & (2) & & (1) & (2) & & (1) & (2) \\
\hline Trial & $-0.13034^{\star \star \star}(-5.99)$ & $-0.047107^{\star \star \star}(-2.97)$ & Trial & $-0.520371^{\star \star \star}(-5.30)$ & $-0.1277243^{\star \star}(-2.39)$ & Trial & $0.4598315^{\star \star \star}(13.31)$ & $0.0454864^{\star \star \star}(5.08)$ \\
\hline Structure & & $-0.9026371^{\star \star \star}(-13.29)$ & Pop & & $0.0003421^{\star \star}(1.50)$ & Patent & & $2.59 \mathrm{e}-07^{\star \star}(2.19)$ \\
\hline Industry & & $0.0503638(1.00)$ & Industry & & $-0.5686398^{\star \star \star}(-2.86)$ & Trade & & $0.0785542^{\star \star \star}(2.67)$ \\
\hline GDP & & $-6.59 \mathrm{e}-06^{\star \star \star}(-4.09)$ & Patent & & $-1.08 \mathrm{e}-07(-0.15)$ & Market & & $0.0012467(0.26)$ \\
\hline Pop & & $0.000211^{\star \star \star}(3.30)$ & Endowment & & $0.1902854^{\star \star \star}(2.60)$ & Pop & & $-0.0001894^{\star \star \star}(-6.02)$ \\
\hline Endowment & & $0.0677538^{\star \star \star}(2.84)$ & Urban & & $-0.0809034^{\star \star \star}(-6.23)$ & Urban & & $0.0186329^{\star \star \star}(10.36)$ \\
\hline Constant & $10.13965^{\star \star \star}(1,550.62)$ & $9.456737^{\star \star \star}(37.41)$ & Constant & $2.127956^{\star \star \star}(77.37)$ & $5.333,662^{\star \star \star}(5.09)$ & Constant & $\begin{array}{c}10.51116^{\star \star \star} \\
(2,490.22)\end{array}$ & $10.33722^{\star \star \star}(62.80)$ \\
\hline Observations & 360 & 360 & Observations & 360 & 360 & Observations & 360 & 360 \\
\hline Control variables & No & Yes & Control variables & No & Yes & Controls & No & Yes \\
\hline Within- $R^{2}$ & 0.0712 & 0.5427 & Within- $R^{2}$ & 0.0786 & 0.2218 & Within- $R^{2}$ & 0.1636 & 0.5614 \\
\hline Year, province fixed & Yes & Yes & Year, province fixed & Yes & Yes & Year, province fixed & Yes & Yes \\
\hline
\end{tabular}

${ }^{2}$ Note: $t$-values are in parentheses, ${ }^{* *} p<0.01,{ }^{* *} p<0.05,{ }^{*} p<0.1$.

TABLE 5 | Robustness test results.

\section{InCO2}

(1) (2)

\begin{tabular}{|c|c|c|c|}
\hline Trial & $-0.0246595^{\star \star \star}(-2.77)$ & $0.037463(0.92)$ & Trial \\
\hline Structure & $-1.489968^{\star \star \star}(-47.10)$ & $-1.191445^{\star \star \star}(-12.53)$ & Pop \\
\hline Industry & $-0.0614666^{\star \star \star}(-2.33)$ & $0.1735929^{\star \star}(2.01)$ & Industry \\
\hline GDP & $0.0000208^{\star \star \star}(28.17)$ & $0.0000176^{\star \star \star}(8.35)$ & Patent \\
\hline Pop & $0.0001992^{\star \star \star}(28.39)$ & $00.0001145^{\star \star \star}(8.43)$ & Endowment \\
\hline Endowment & $0.0280681^{\star \star \star}(4.40)$ & $0.0543027^{\star \star \star}(3.92)$ & Urban \\
\hline Constant & $8.827886^{\star \star \star}(139.66)$ & $9.239198^{* * \star}(73.54)$ & Constant \\
\hline Observations & 360 & 360 & Observations \\
\hline Control variables & Yes & Yes & Controls \\
\hline$R^{2}$ & & 0.8231 & $R^{2}$ \\
\hline Year, province fixed & Yes & Yes & Year, province fixed \\
\hline
\end{tabular}

\section{CO2int}

(1)

$\begin{array}{ccl}-0.066776^{\star \star \star}(-2.88) & -0.0766193(-0.65) & \text { Trial } \\ -0.000141^{\star \star \star}(-38.37) & -0.000121^{\star \star \star}(-4.42) & \text { Patent } \\ 0.2324867^{\star \star \star}(7.18) & 0.2672839(1.11) & \text { Trade } \\ -8.62 \mathrm{e}-07^{\star \star \star}(-16.40) & 8.37 \mathrm{e}-07(0.80) & \text { Market } \\ 0.4074867^{\star \star \star}(78.84) & 0.49242^{\star \star \star}(17.87) & \text { Pop } \\ -0.046851^{\star \star \star}(-72.34) & -0.03374^{\star \star \star}(-6.70) & \text { Urban } \\ 4.490066^{\star \star \star}(71.52) & 3.963777^{\star \star \star}(8.72) & \text { Constant } \\ 360 & 360 & \text { Observations } \\ \text { Yes } & \text { Yes } & \text { Controls } \\ & 0.6696 & R^{2} \\ \text { Yes } & \text { Yes } & \text { Year, province fixed }\end{array}$

InGDPave

(1)

$\begin{array}{cl}0.0443021^{\star \star}(2.47) & 0.0082539(0.56) \\ 8.80 \mathrm{e}-07^{\star \star \star}(4.82) & 5.71 \mathrm{e}-07^{\star \star \star}(3.25) \\ -0.3284773^{\star \star \star}(-11.42) & -0.3145789^{\star \star \star}(-6.69) \\ 0.0458852^{\star \star \star}(4.98) & -0.0088443(-0.95) \\ 0.0000245^{\star \star \star}(4.65) & 0.0000263^{\star \star \star}(5.92) \\ 0.0360387^{\star \star \star}(27.20) & 0.0394321^{\star \star \star}(25.10) \\ 43,229.82^{\star \star \star}(172.35) & 8.171229^{\star \star \star}(128.36) \\ 360 & 360 \\ \text { Yes } & \text { Yes } \\ & 0.9229 \\ \text { Yws } & \text { Yes }\end{array}$

${ }^{3}$ Note: column (1): FGLS, regression results; column (2): counterfactual test results. $z$-values are in parentheses of (1) $t$-values are in parentheses of (2), ${ }^{* *} p<0.01,{ }^{* *} p<0.05,{ }^{*} p<0.1$. 
intensity in the pilot areas and promote regional economic growth.

\section{Robustness Test}

For further verifying the reliability and robustness of the benchmark results, two robustness tests are done in this paper. Firstly, the comprehensive feasible generalized least squares (FGLS) method is utilized to regress again. When using panel data analysis, we may encounter problems like inter-group heteroscedasticity, intra-group autocorrelation, and inter-group contemporaneous correlation, which will affect the robustness and consistency of the estimation results (Xue and Zhou, 2021). Therefore, this paper uses comprehensive FGLS to regress the three models, and the regression results are shown in column 1) Table 5, the coefficient of the trial of each model is still significant and we can draw the same conclusion as benchmark regression that carbon market policy can markedly promote carbon reduction and economic growth. Secondly, the counterfactual test is conducted by randomly selecting eight provinces as the treatment group, taking 2014 as the year of policy implementation, building a "false" dummy variable of carbon emission trading pilot, and carrying out the same regression as benchmark regression. If we obtain the same conclusion as the benchmark regression, then the previous regression result we get is questionable. Otherwise, the conclusion of this paper has a certain degree of credibility (Huang et al., 2018). Through random sampling, it can be observed in the regression results that the coefficients of the "false" policy dummy variable trial are all not significant, and the robustness test is passed. A group of test results have been selected and set forth in column 2) of Table 5.

\section{Discussion}

From the above empirical analysis, it can be seen that the emission reduction effect of the carbon market and the economic growth effect of the carbon market have been verified, which shows that China's carbon market pilot can indeed reduce China's carbon emissions, and help China achieve the goal of carbon neutralization and carbon peak, and also prove that the national carbon market is feasible and effective. However, from the perspective of coefficient, the emission reduction effect and economic growth effect of setting up a carbon market are not particularly good. In addition to the coefficient of control variables, there is a significant positive correlation between GDP and carbon emissions, which shows that China is still in the stage of extensive economic growth, and economic development increases carbon emissions. There is a significant negative correlation between urbanization rate and total carbon emissions, but it also significantly promotes economic growth, indicating that urbanization has an obvious effect on promoting economic growth and reducing the intensity of carbon emissions. The population has a significant negative correlation with carbon emissions and carbon intensity, indicating that population growth will bring more carbon emissions. As China's main emission reduction policy means, the carbon trading market has high expectations from the Chinese government. If we want to give further play to the emission reduction effect of the carbon market, we must understand the emission reduction mechanism of the carbon market, study the impact of factors such as carbon price and marketization on the emission reduction effect of the carbon market, and implement the combination of government intervention and market mechanisms to maximize the benefit of carbon market policy. Therefore, this paper continues to study the carbon reduction mechanism of the carbon market and the impact of a carbon price and marketization on the effectiveness of the carbon market.

\section{MECHANISM RESEARCH}

\section{Intermediary Effect Test}

According to the above analysis, carbon emission trading plays a significant role in reducing carbon dioxide emissions in pilot provinces and cities. But how does carbon emission trading affect carbon dioxide emissions in pilot provinces and cities? This paper uses Sobel intermediary effect test method to test the intermediary effect of three relevant variables in the impact of carbon emission trading on carbon emission reduction, intermediary variables include energy consumption structure, scientific and technological innovation, and industrial structure which are represented by the variables: structure, patent, and industry, respectively ${ }^{1}$. The explanation of these variables is the same as Table 1, that is, the carbon market affects the carbon emission $\operatorname{lnCO}_{2}$ through the influence of he variable sstructure, patent, and industry. The test of the product of coefficients is the core of the test of intermediary effect, assume Coefficient a is the effect of an independent variable on an intermediate variable; Coefficient $b$ is the effect of an intermediate variable on $a$ dependent variable after controlling the influence of the independent variable. The Sobel test determines the existence of mediating effects by calculating Sobel test statistics to examine whether the product of $a, b$ is significantly not 0 (Wen and ye, 2014).

Based on the theory and benchmark models above, the models for mediating effect test are formed below:

$$
\begin{gathered}
M_{i t}=\beta_{0}+\beta_{1} \text { Trial }_{i t}+\beta_{2} X_{i t}+\mu_{i}+\varphi_{t}+\varepsilon_{i t} \\
\ln C O 2_{i t}=\beta_{0}+\beta_{3} M_{i t}+\beta_{4} X_{i t}+\mu_{i}+\varphi_{t}+\varepsilon_{i t} \\
\operatorname{lnCO2} 2_{i t}=\beta_{0}+\beta_{5} M_{i t}+\beta_{6} \text { Trial }_{i t}+\beta_{7} X_{i t}+\mu_{i}+\varphi_{t}+\varepsilon_{i t}
\end{gathered}
$$

Where $M$ represents the intermediary variables Structure, Industry, and Patent, respectively. If $\beta_{1}, \beta_{3}$, and $\beta_{5}$ are all significant, it can be explained that the carbon trading market reduces carbon emissions by affecting the intermediary variables.

\section{Test Results}

The outcome of the Sobel test is depicted in Table 6. The $p$-value corresponding to the intermediary effect of energy consumption structure, industrial structure, and scientific and technological innovation is significantly less than 0.01 , and the Sobel value is significant at the level of $1 \%$, indicating that the Sobel intermediary effect test of these three variables has passed, that is, energy consumption structure, industrial structure, and 
TABLE 6 | Sobel test results.

\begin{tabular}{|c|c|c|c|c|c|}
\hline Variables & Items & Coefficient & Standard error & $\begin{array}{c}Z \text { value/t } \\
\text { value }\end{array}$ & $P>|Z| / P>|t|$ \\
\hline Structure & $\begin{array}{l}\text { Mediating effect (Sobel value) } \\
\text { Direct effect } \\
\text { Total effect } \\
\text { Proportion of intermediary effect }\end{array}$ & $\begin{array}{c}-0.22071088 \\
-0.0737649 \\
-0.2944758 \\
74.95 \%\end{array}$ & $\begin{array}{c}0.04195397 \\
0.0445621 \\
0.0585232\end{array}$ & $\begin{array}{l}-5.26 \\
-1.66 \\
-5.03\end{array}$ & $\begin{array}{l}1.4 \mathrm{e}-7 \\
0.099 \\
0.000\end{array}$ \\
\hline Industry & $\begin{array}{l}\text { Mediating effect (Sobel value) } \\
\text { Direct effect } \\
\text { Total effect } \\
\text { Proportion of intermediary effect }\end{array}$ & $\begin{array}{c}-0.01240858 \\
-0.0753906 \\
-0.0877992 \\
14.13 \%\end{array}$ & $\begin{array}{c}0.00427989 \\
0.0439793 \\
0.0441259\end{array}$ & $\begin{array}{l}-2.899 \\
-1.71 \\
-1.99\end{array}$ & $\begin{array}{c}0.00374027 \\
0.087 \\
0.047\end{array}$ \\
\hline Patent & $\begin{array}{l}\text { Mediating effect (Sobel value) } \\
\text { Direct effect } \\
\text { Total effect } \\
\text { Proportion of intermediary effect }\end{array}$ & $\begin{array}{c}-0.02372946 \\
-0.3155082 \\
-0.3392377 \\
6.99 \%\end{array}$ & $\begin{array}{l}0.00814258 \\
0.0580275 \\
0.0573733\end{array}$ & $\begin{array}{l}-2.914 \\
-5.44 \\
-5.91\end{array}$ & $\begin{array}{l}0.00356551 \\
0.000 \\
0.000\end{array}$ \\
\hline
\end{tabular}

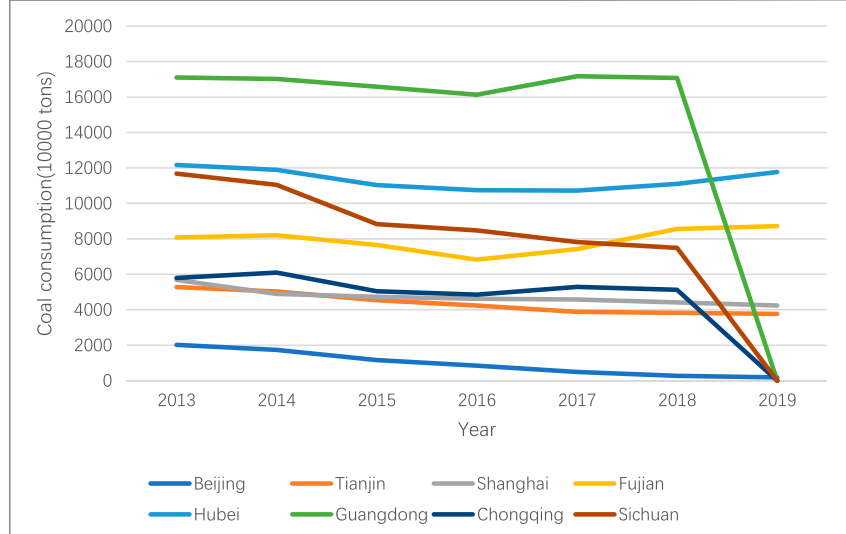

FIGURE 3 | Coal consumption in pilot areas after 2013.

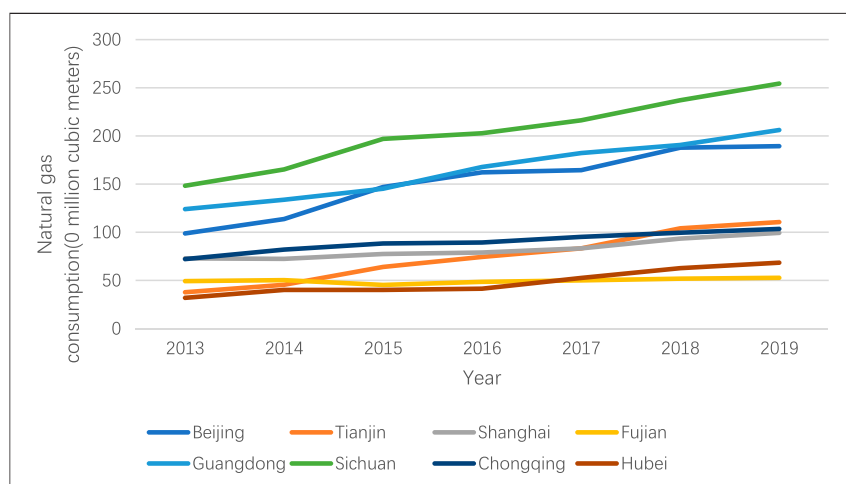

FIGURE 4 | Natural gas consumption in pilot areas after 2013.

scientific and technological innovation have played a significant intermediary effect in the impact of carbon emission trading on carbon dioxide emissions, the mediation effect proportions are $74.95,14.13$, and $6.99 \%$, respectively.

The test results above suggest that the energy consumption structure is the main way the carbon market is utilized to reduce carbon emissions; low carbon innovation and industrial structure are other carbon emission reduction means of the carbon market policy. Under the current industrial structure of enterprises, it is difficult to suddenly change an industry, and investment in green technology innovation is often slow to achieve results. Moreover, China is now in the primary stage of its carbon market, thus, enterprises will choose to reduce the use of high carbon emission energy and use clean energy instead. The proportion of natural gas in energy consumption is increasing year by year, while the coal consumption is decreasing year by year after 2013 as is illustrated in Figures 3, 4 (National data, China National Bureau of Statistics, 2021). Therefore, changing the energy structure is the principal channel for the emission reduction effect of this carbon market.

Figure 5 depicts the emission reduction mechanism of the carbon market.

According to Figure 5, the emission reduction mechanism of the carbon market can be briefly summarized as follows: First, the carbon market restricts the cost of enterprises by limiting quotas. Therefore, enterprises will directly adjust the industrial structure and turn to industries with low emissions, such as high-tech industries, or adjust the energy structure by reducing the use of fossil energy and using more clean energy to achieve carbon emission reduction; Second, carbon trading forces enterprises, especially high carbon emission enterprises, to carry out low-carbon innovation through market incentives. At the same time, enterprises can sell excess carbon quotas through the market, so as to reasonably allocate resources to achieve carbon emission reduction and promote economic growth.

\section{INFLUENCE OF CARBON PRICE MARKET ON EMISSION REDUCTION EFFECT OF THE CARBON MARKET}

Carbon pricing is the core of carbon market policy, which curbs carbon emissions by placing a fee on carbon-emitting. A carbon price signal shifts consumption and investment patterns, making economic growth go along with environmental protection 


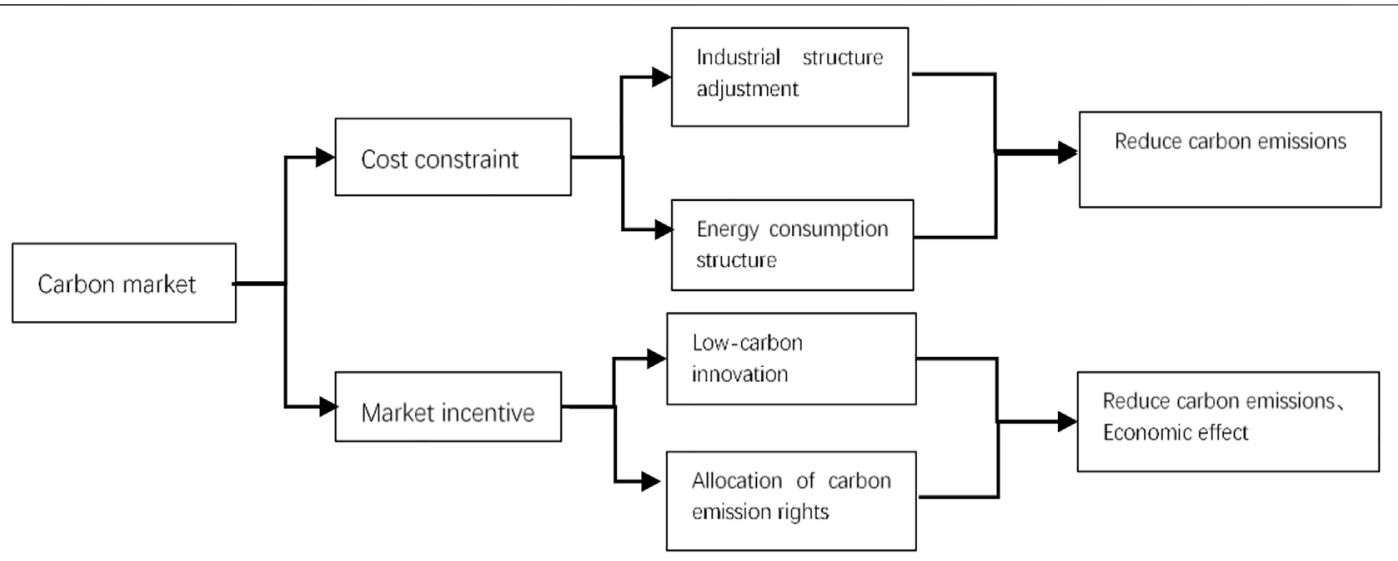

FIGURE 5 | Carbon market mechanism.

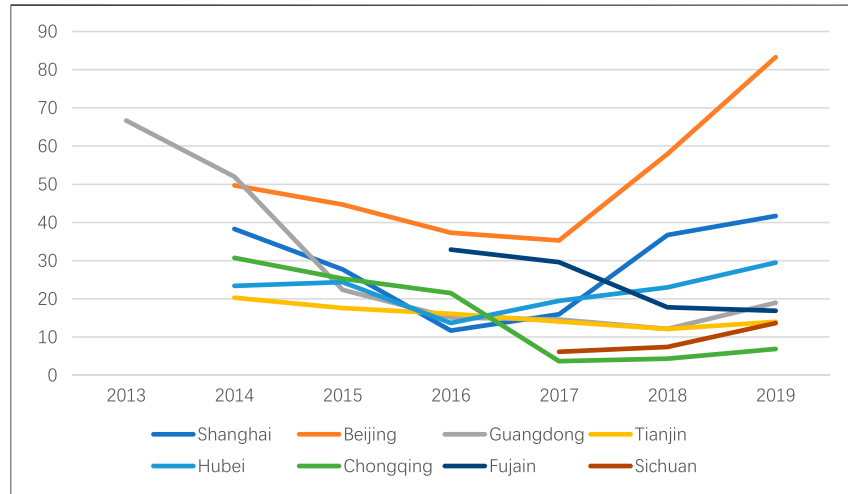

FIGURE 6 | Average annual carbon price of pilot areas.

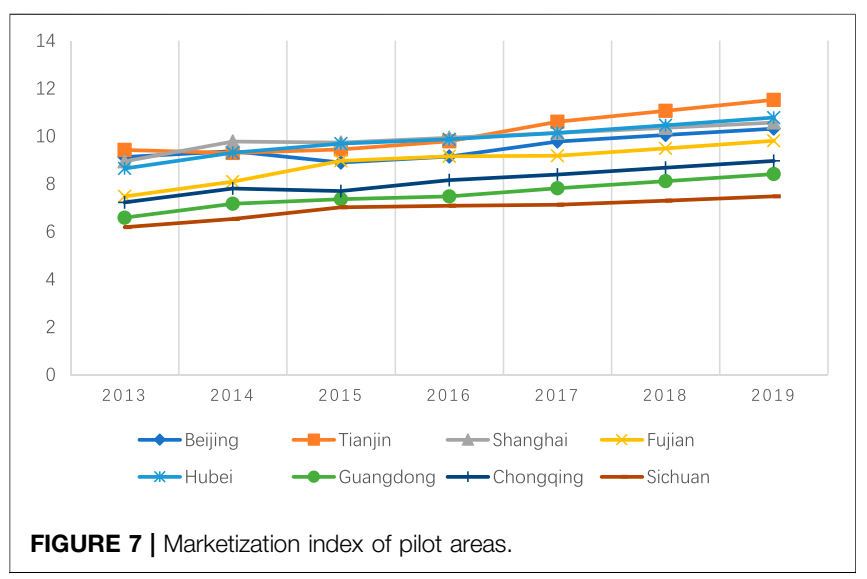

(United Nations Climate Change, 2021). In addition, the essence of the carbon market is that it is a market, and the price is an important means of regulating the market. At the same time, the degree of regional marketization also affects the effectiveness of the carbon price signal. The average annual carbon price of pilot areas and marketization index of pilot areas from 2013 to 2019 is illustrated in Figures 6, 7.
As the value of variable Trial is one only in pilot time in the pilot area, otherwise it is 0 , the interaction term price ${ }^{\star}$ trial and market ${ }^{\star}$ trial will Contain the same meaning as trial, also, variable Price is equal to price ${ }^{\star}$ trial, for avoiding regression problems we omit these terms. In view of the theoretical analysis from the perspective of carbon price and marketization above, the following models incorporating carbon price and marketization are designed to test the concept.

$$
\begin{aligned}
\ln C O_{2} & =\beta_{0}+\beta_{1} \text { trial } * \text { price }+\beta_{2} X_{i t}+\mu_{i}+\varphi_{t}+\varepsilon_{i t} \\
\ln C O_{2}= & \alpha_{0}+\alpha_{1} \text { trial } * \text { market }+\alpha_{2} \text { market }+\alpha_{3} X_{i t}+\mu_{i}+\varphi_{t} \\
& +\varepsilon_{i t}
\end{aligned}
$$

Where the variable Price is the average annual carbon price of the pilot province in the pilot year, (Carbon price comes from carbon exchange of each pilot area.) other variables are the same as above. The results are presented in Table 7.

Consider the meaning of the interaction term, that is, the marginal effect of carbon trading emission reduction effect is affected by the carbon price and marketization. In the fourcolumn regression results, the coefficients of Trial ${ }^{\star}$ price and Trial $^{*}$ market are significantly positive at the level of $1 \%$, indicating that the carbon trading emission reduction effect increases with the increase of carbon price and marketization. Thus, the result is highly compatible with the theory discussed previously.

\section{CONCLUSION AND RECOMMENDATIONS}

Through empirical research and discussion above, the following conclusions are put forward: 1) carbon emissions trading can reduce carbon emissions in pilot areas and promote regional economic growth. 2) The carbon market mainly realizes carbon emission reduction by changing the regional energy consumption structure and adjusting the industrial structure, as well as promoting green scientific and technological innovation. 3) 
TABLE 7 | Impact of carbon price and marketization on carbon reduction effect of the carbon market.

\begin{tabular}{|c|c|c|c|c|c|}
\hline & \multicolumn{2}{|c|}{$\operatorname{lnCO} 2$} & & \multicolumn{2}{|c|}{$\operatorname{lnCO2}$} \\
\hline & (1) & (2) & & (3) & (4) \\
\hline Trial ${ }_{\star}$ Price & $-0.0030218^{\star \star \star}(-4.96)$ & $-0.0011368^{\star \star \star}(-2.91)$ & MarketTrial & $-0.0216974^{\star \star \star}(-5.23)$ & $-0.0042142 * \star(-2.14)$ \\
\hline Structure & & $-0.9149385^{\star \star \star}(-10.97)$ & Structure & & $-0.910557^{\star \star \star}(-10.63)$ \\
\hline Industry & & $0.049565^{\star \star \star}(0.98)$ & Industry & & 0.0491819 (0.96) \\
\hline GDP & & $-6.61 \mathrm{e}-06^{\star \star \star}(-4.08)$ & GDP & & $-6.58 \mathrm{e}-06^{\star \star \star}(-4.10)$ \\
\hline Pop & & $0.0001941^{\star \star \star}(3.1)$ & Pop & & $0.0002109^{\star \star \star}(3.19)$ \\
\hline \multirow[t]{2}{*}{ Endowment } & & $0.0672824^{\star \star \star}(2.81)$ & Endowment & & $0.0674016^{\star \star \star}(2.76)$ \\
\hline & & & Market & $0.1542389^{\star \star \star}(12.61)$ & $-0.0014619(-0.11)$ \\
\hline Constant & $10.13318^{\star \star \star}(1,617.42)$ & $9.536561^{\star \star \star}(39.17)$ & Constant & $9.154773^{\star \star \star}(119.72)$ & $9.46937^{\star \star \star}(37.62)$ \\
\hline Observations & 360 & 360 & Observations & 360 & 360 \\
\hline Control variables & No & Yes & Control variables & No & Yes \\
\hline $\mathrm{R}^{2}$ & 0.9906 & 0.9805 & $\mathrm{R}^{2}$ & 0.3380 & 0.9906 \\
\hline Year, province fixed & Yes & Yes & Year, province fixed & Yes & Yes \\
\hline
\end{tabular}

Carbon price signal and regional marketization level have a positive impact on the emission reduction effect of the carbon market.

It can be seen from the above conclusions that, on the whole, the carbon market has a significant carbon emission reduction effect on the pilot areas, which can reduce carbon emissions and carbon intensity at the same time, and the carbon market can also promote economic growth. However, as China's main emission reduction policy, the emission reduction effect of the carbon market still needs to be strengthened. Moreover, throughout the research, this paper also found that the carbon price and the degree of marketization will affect the emission reduction effect of the carbon market. The carbon price signal is the embodiment of the activity of the carbon trading market. A lower carbon price will make the carbon market lose its vitality, and marketization is an important premise of the carbon market, that is, as a market, the carbon market must be supported by a certain degree of marketization in order to effectively reduce carbon emission. However, since the opening of China's national carbon market, the carbon price has kept falling, and the average transaction price has continuously decreased from 50.33 yuan per ton in July 2021 to 41.46 yuan per ton in September 2021 (Shanghai environment and energy exchange, 2021). Thus, the carbon emission reduction effect of China's carbon trading market mechanism is limited, and when the market mechanism fails, government intervention can significantly enhance the carbon emission reduction effect of the carbon market. Therefore, China should pay more attention to achieving carbon emission reduction through the synergy of the market mechanism and regional administrative intervention.

In view of the above results and analyses, the following suggestions are given: 1) Guide enterprises to upgrade and transform their industrial structure, strengthen low-carbon technology innovation, develop and utilize clean energy to promote the optimization of energy structure. 2) Adhere to market orientation, bring the incentive role of carbon price signal into play, and regulate the carbon market by marketoriented means. 3) A series of binding national laws and regulations must be issued to clarify the responsibilities of the administrative department in charge of the carbon market and the responsibilities and obligations of the main body of the carbon market. 4) Stick to the main role and basic role of the market in resource allocation of the carbon market, vigorously develop carbon finance, launch carbon emission trading derivatives, build a diversified carbon finance trading platform, guide investors to participate in it, and improve the activity of the market. 5) Give play to the synergy between carbon trading and other environmental regulations, and explore the synergy and complementarity mode of relevant systems.

For further research, researchers should start with the microstructure of the carbon market, and study how to further exert the regulation role of the carbon market and maximize the emission reduction role of the carbon market. More specifically, for China's carbon market, it is necessary to discuss in-depth how to further enhance the role of the carbon market in reducing emissions through government intervention and the coordination of market-based mechanisms, to help China achieve its goal of carbon neutrality ahead of schedule, and to contribute to the improvement of the world's environment.

\section{DATA AVAILABILITY STATEMENT}

The original contributions presented in the study are included in the article/Supplementary Material, further inquiries can be directed to the corresponding author.

\section{AUTHOR CONTRIBUTIONS}

The author confirms being the sole contributor of this work and has approved it for publication.

\section{SUPPLEMENTARY MATERIAL}

The Supplementary Material for this article can be found online at: https://www.frontiersin.org/articles/10.3389/fenvs.2021.787655/ full\#supplementary-material 


\section{REFERENCES}

Anger, N. (2008). Emissions Trading Beyond Europe: Linking Schemes in a PostKyoto World[J]. Energ. Econ. 30, 2028-2049. doi:10.1016/j.eneco.2007.08.002 BP (2021). Statistical Review of World Energy. Available at: https://www.bp.com/ content/dam/bp/business-sites/en/global/corporate/pdfs/energy-economics/ statistical-review/bp-stats-review-2020-full-report.pdf.

Chen, W., and Jin, X. (2016). Carbon Emissions and Regional Economic Growth -- an Empirical Analysis Based on Inter Provincial Panel Data from 2000 to 20[J]. Macroeconomic Res. (10), 121-132154. doi:10.16304/j.cnki.11-3952/f.2016.10.013

China Launches World (2021). China Launches World's Largest Carbon Market: but Is it Ambitious Enough? Nature. 595, 637. doi:10.1038/d41586-021-01989-7

Chinese government (2021). Available at: http://www.gov.cn/xinwen/2021-07/16/ content_5625374.htm.

Coase, R. H. (1960). The Problem of Social Cost. J. L. Econ. 3, 1-44. doi:10.1002/ sres.3850090105

Fernández-Amador, O., Francois, J. F., Oberdabernig, D. A., and Tomberger, P. (2017). Carbon Dioxide Emissions and Economic Growth: An Assessment Based on Production and Consumption Emission Inventories. Ecol. Econ. 135, 269-279. doi:10.1016/j.ecolecon.2017.01.004

$\mathrm{Fu}$, J., and Zou, H. (2017). Effect of Carbon price on Competitiveness and Emission Reduction of China's Industrial Sector [J]. Res. Sci. Technol. Manag. 37 (07), 234-241. doi:10.3969/j.issn.1000-7695.2017.07.035

Gao, Y., Li, M., Xue, J., and Liu, Y. (2020). Evaluation of Effectiveness of China's Carbon Emissions Trading Scheme in Carbon Mitigation. Energ. Econ. 90, 104872. doi:10.1016/j.eneco.2020.104872

Guidelines for the preparation of provincial greenhouse gas inventories (2014). Available at: http://www.cbcsd.org.cn/sjk/nengyuan/standard/home/.

Hu, Y., and Ding, Y. (2020). Can the Carbon Emission Trading Mechanism Give Consideration to enterprise Benefits and green Efficiency [ J]. China's Popul. Resour. Environ. 30 (03), 56-64. doi:10.12062/cpre.20191112

Hua, Y., and Dong, F. (2019). China's Carbon Market Development and Carbon Market Connection: A Literature Review. Energies. 12, 1663. doi:10.3390/ en12091663

Huang, D., Chen, J., and Zhou, H. (2016). Research on Dynamic Batch Production and Emission Reduction Investment Strategy Under Quota Trading Mechanism [J]. China Manag. Sci. 24 (04), 129-137. doi:10.16381/ j.cnki.issn1003-207x.2016.04.015

Huang, X., Zhang, X., and Liu, Y. (2018). Has China's Carbon Trading Policy Achieved Environmental Dividends [J]. Econ. Rev. 2018 (06), 86-99. doi:10.19361/j.er.2018.06.07

Imbens, G. W., and Wooldridge, J. M. (2009). Recent Developments in the Econometrics of Program Evaluation[ J]. J. Econ. Lit. 47, 5-86. doi:10.3386/ w14251

Kou, J. (2021). Using Market Mechanism to Promote Carbon Emission Reduction. People's Daily, June 29,2021, 10th edition. http://finance.people.com.cn/n1/ 2021/0629/c1004-32143305.html.

Li, L., Liu, Q., Wang, J., and Hong, X. (2019). Carbon Information Disclosure, Marketization, and Cost of Equity Financing. Int. J. Environ. Res. Public Health. 16, 150. doi:10.3390/ijerph16010150

Lili, W., and Ren, L. (2021). Can Carbon Emission Trading Promote Enterprise Green Technology Innovation -- from the Perspective of Carbon price [J]. Lanzhou J. 2021 (07), 91-110.

Lo, A. Y. (2012). Carbon Emissions Trading in China. Nat. Clim Change. 2 (11), 765-766. doi:10.1038/nclimate1714

Lokhov, R., and Welsch, H. (2008). Emissions Trading between Russia and the European Union: A CGE Analysis of Potentials and Impacts. Environ. Econ. Pol. Stud. 9, 1-23. doi:10.1007/BF03353972

Marketization Index of China's Provinces (2018). NERI Report 2018 by Fan Gang. Beijing, China: Xiaolu Wang, Gang Fan, Lipeng Hu. Available at: https://cmi. ssap.com.cn/.
National data, China National Bureau of Statistics (2021). Available at: https://data. stats.gov.cn/easyquery.htm?cn=E0103.

Shanghai environment and energy exchange (2021). Available at: https://www. cneeex.com/qgtpfqjy/jysj/ydgk/.

Tang, B-J. (2020). Optimal Carbon Allowance price in China's Carbon Emission Trading System: Perspective From the Multi-Sectoral Marginal Abatement Cost [J]. J. Clean. Prod. 253, 119945. doi:10.1016/j.jclepro.2019.119945

United Nations Climate Change (2021). Available at: https://unfccc.int/about-us/ regional-collaboration-centres/the-ci-aca-initiative/about-carbon-pricing\#eq-3.

Wang, H., and Yao, W. (2021). Policy Effect and Impact Mechanism of Carbon Emission Trading in Pilot Cities in China [J]. Urban Dev. Res. 28 (06), 133-140. doi:10.18402/resci.2019.03.12

Wen, Z., and ye, B. (2014). Mediating Effect Analysis: Method and Model Development [J]. Psychol. Sci. exhibition. 22 (05), 731-745. doi:10.3724/ sp.j.1042.2014.00731

Wu, D. (2018). Comparative Analysis of Carbon Emission Trading Effects Based on Porter hypothesis $[D]$. Lanzhou: Lanzhou University.

Wu, J., Cui, C., Mei, X., Xu, Q., and Zhang, P. (2021a). Migration of Manufacturing Industries and Transfer of Carbon Emissions Embodied in Trade: Empirical Evidence From China and Thailand. Environ. Sci. Pollut. Res. doi:10.1007/ s11356-021-14674-z

Wu, Q., Tambunlertchai, K., and Pornchaiwiseskul, P. (2021b). Examining the Impact and Influencing Channels of Carbon Emission Trading Pilot Markets in China. Sustainability. 13, 5664. doi:10.3390/su13105664

Xuan, D., Ma, X., and Shang, Y. (2020). Can China's Policy of Carbon Emission Trading Promote Carbon Emission Reduction? J. Clean. Prod. 270, 122383. doi:10.1016/j.jclepro.2020.122383

Xue, F., and Zhou, M. (2021). Study on the Emission Reduction Effect of the Scale of China's Carbon Trading Market [J]. East China Econ. Manag. 35 (06), 11-21. doi:10.19629/j.cnki.34-1014/f.201211011

Yin-yin, W., Qi, J., Xian, Q., and Chen, J-d. (2021). The Carbon Emission Reduction Effect of China's Carbon Market--From the Perspective of the Coordination Between Market Mechanism and Administrative Intervention [J]. China Industrial Economy. 401 (08), 114-132. doi:10.19581/ j.cnki.ciejournal.2021.08.007

Zhang, H., Duan, M., and Deng, Z. (2019). Have China's Pilot Emissions Trading Schemes Promoted Carbon Emission Reductions? the Evidence From Industrial sub-Sectors at the Provincial Level. J. Clean. Prod. 234, 912-924. doi:10.1016/j.jclepro.2019.06.247

Zhao, L., Zhang, L., Li, R., and Yang, M. (2013). Energy Endowment, Human Capital and China's Green Economic Performance [J]. Contemp. Econ. Sci. 35 (04), 74-84. doi:10.32629/ej.v3i2.419

Zhong, S., Xin, C., Shen, H., and Chen, X. (2021). Effects of Land Urbanization and Internet Penetration on Environmental Sustainability: a Cross-Regional Study of China. Environ. Sci. Pollut. Res. doi:10.1007/s11356-021-15226-1

Conflict of Interest: The author declares that the research was conducted in the absence of any commercial or financial relationships that could be construed as a potential conflict of interest.

Publisher's Note: All claims expressed in this article are solely those of the authors and do not necessarily represent those of their affiliated organizations, or those of the publisher, the editors and the reviewers. Any product that may be evaluated in this article, or claim that may be made by its manufacturer, is not guaranteed or endorsed by the publisher.

Copyright $\odot 2021 \mathrm{Xu}$. This is an open-access article distributed under the terms of the Creative Commons Attribution License (CC BY). The use, distribution or reproduction in other forums is permitted, provided the original author(s) and the copyright owner(s) are credited and that the original publication in this journal is cited, in accordance with accepted academic practice. No use, distribution or reproduction is permitted which does not comply with these terms. 